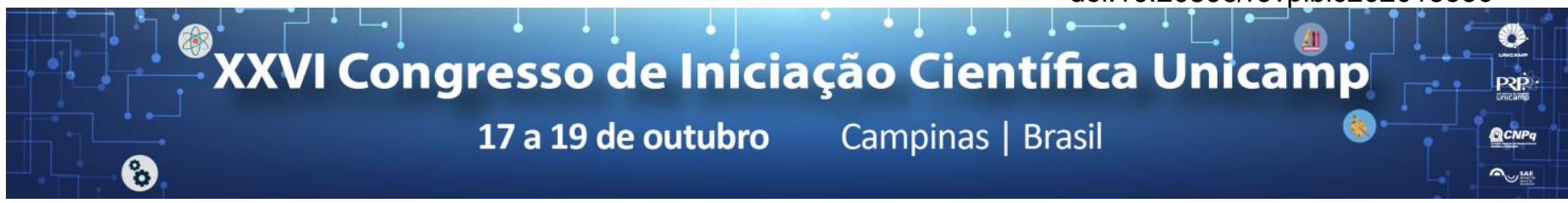

\title{
Ferramenta de Modelagem de Ciclos de Vida de Dados para Apoio na Gestão de Tecnologia da Informação
}

\section{Gregory Dias Marques*, Luiz Camolesi Junior}

\section{Resumo}

Atualmente, organizações de grande porte têm grande dificuldade em otimizar o uso de suas informações em seu processos, pelo simples desconhecimento dos Ciclos de Vida destas informações. O objetivo deste trabalho é o desenvolvimento de uma ferramenta para a modelagem não diagramática dos Ciclos de Vida para uso em ambiente organizacional. A modelagem é realizada por uma interface gráfica em que as dimensões de maior impacto para a rastreabilidade, tais como atores, processos e softwares, são registradas e inter-relacionadas, permitindo uma visualização, monitoramento e controle efeito sobre os Ciclos de Vida.

\section{Palavras-chave:}

Ciclo de Vida de Dados, Rastreabilidade, Gestão de Dados.

\section{Introdução}

Devido à competitividade acirrada em muitos mercados, torna-se importante gerenciar o grande volume de dados e informações existentes nos ambientes organizacionais. A capacidade de gestão é uma vantagem competitiva em relação aos concorrentes, desde que realizada com eficácia e eficácia. Prezar pela qualidade e segurança na trajetória dos dados e informações entre os processos de uma organização tem sido um grande desafio, pois envolve o monitoramento durante todo o Ciclo de Vida dos dados, desde sua criação até a eliminação.

Motivado por esta realidade, o objetivo deste trabalho é o desenvolvimento de uma ferramenta para a modelagem não diagramática dos Ciclos de Vida para uso em ambiente organizacional.

\section{Resultados e Discussão}

As dimensões de maior impacto na rastreabilidade do Ciclo de Vida que a ferramenta atendeu permitem um ganho significativo na abrangência. Devido à necessidade de inter-relação entre todas as dimensões, foi utilizado o Modelo de Dados apresentado na Figura 1. A classe Ação permite a inter-relação entre as dimensões: informação (entidade, relacionamento e cardinalidade); processo e atividade; ator; software; fase do ciclo de vida; e a operação (ex: CRUD).

Figura 1. Modelo de Dados

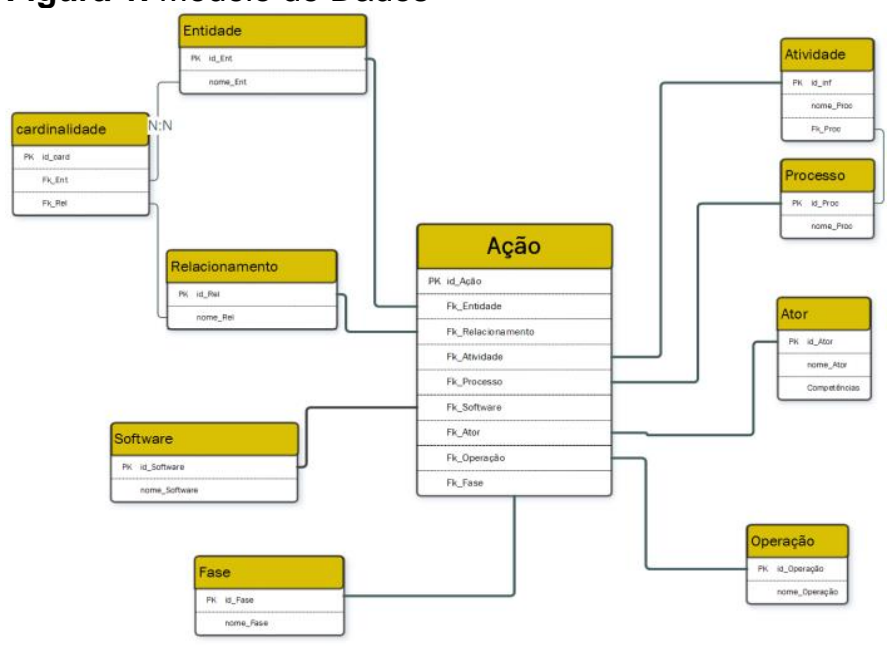

A Figura 2 apresenta uma das interfaces da ferramenta, pela qual é possível editar uma ação através da seleção das respectivas dimensões envolvidas.

Figura 2. Cadastro da Ação

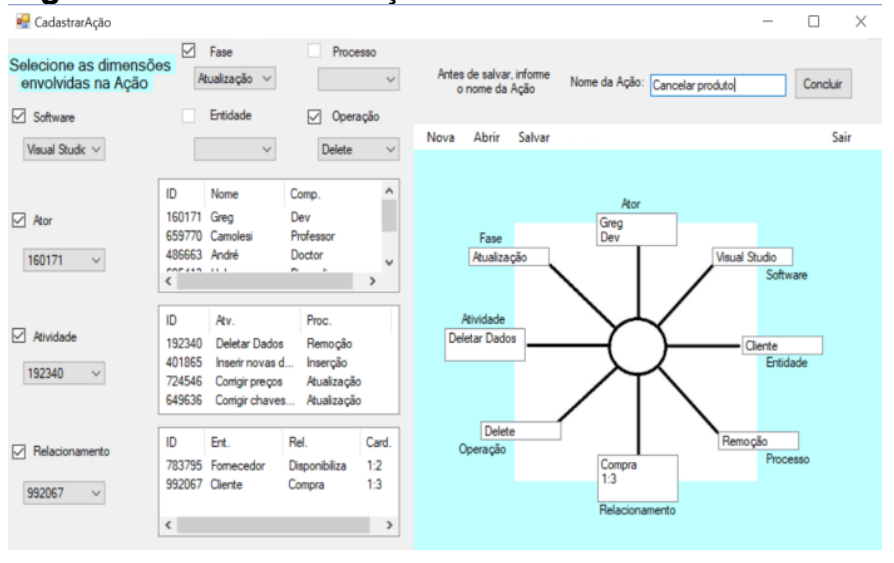

A ferramenta possui a funcionalidade da verificação de integridade que alerta o usuário sobre ações que não estão corretamente preenchidas com as dimensões consideradas obrigatórias.

A visualização é outro recurso disponível, com a utilização de matrizes bidimensionais que expõem as inter-relações entre duas dimensões selecionadas. Assim, o usuário pode ter uma visão/percepção da existência de ações que envolvem as duas dimensões selecionadas, podendo realizar uma análise, no sentido de identificar necessidades de melhoria, seja por conta da sobrecarga ou baixa utilização de dimensões.

\section{Conclusões}

A ferramenta atualmente permite que o usuário controle e monitore de maneira efetiva o Ciclo de Vida dos dados, com o auxílio de recursos importantes, tais como: armazenamento das dimensões de maneira estruturada, inter-relação entre dimensões de modo completo e flexível, registro de ações e as análises/percepções geradas a partir da visualização por matrizes bidimensionais e da verificação da arquitetura dos dados.

${ }^{1}$ BATINI, C.; SCANNAPIECA, M. - Data Quality: Concepts, Methodologies and Techniques, Springer, 2006. 